Emotional responses of schoolchildren were also identified, which require individual work with a psychologist, for example, such statements as "revive the dog", "I want to cry less at night", "I do not want to hide emotions", "I want children in our class to play quietly", etc.

The children's desires still correspond to what is happening in the world (as in the initial testing), many students also indicate that they would like no "viruses", "no COVID". It is worth noting that there is a positive trend in the responses about desires "for others", for example, health for their loved ones, including personalized desires - water, "so that he is all right", "a pet for my grandmother", "let my parents live longer", "money for all my relatives", " let my friend's headache leave her", etc.

In general, the results of the evaluative stage are focused on determining the level of emotional intelligence and the current state of each schoolchild.

Thus, for the development of the emotional intelligence of primary school children, it is necessary to systematically conduct specially organized classes to develop the ability to express various emotional states, identify and understand the emotions of others.

$$
* * *
$$

1. Izotova, E.I., \& Nikiforova, E.V. (2004). The Emotional Sphere of a Child: Theory and Practice: study manual for students of higher educational establishments. Moscow: Publishing Center "Academy".

2. Nguyen Minh Anh. (2008). Diagnostics of the Level of Emotional Intelligence Development of a Senior Preschooler. Child in Kindergarten, 1, 83-85.

\title{
Malakova N.S. \\ Organization of educational practice on the anthropological ideas
}

Leningrad state University named after A. S. Pushkin

(Russia, St.Peterburg)

doi: 10.18411/scienceconf-09-2021-13

\section{Abstract}

The article is devoted the problem of human solved under the conditions of education. Demonstrated ways of implementation activities: «Human health», «Human and inner world», «Human and outer world». Examples of schools in the city of St. Petersburg, Leningrad and Pskov regions show the "points of growth» anthropological practice. The formation of health-saving way of school life; the disclosure of the value of health meanings of education; developing individual-oriented systems and programs; support for children's giftedness; the establishment of children's organizations, giving the opportunity to find friends, to demonstrate their abilities in socially significant activities. The problem of human all more than fills the field of educational research that speaks about the rise of the anthropological trends in modern education. At the same time, the building of human in education is constrained by factors: the growing ideological vacuum, the formation of a utilitarian approach to the person, destruction of the purity of childhood. Necessary methodological basis for the emerging anthropological practice. The main role should play the teacher, conscious of his high mission of formation of human potential.

Keywords: anthropological ideas, organization of educational practice, Human health, Human and inner world, Human and outer world.

The development of Russian education is carried out in the scale of the challenges, reflecting complex and contradictory process of changing the appearance of civilization, comprehend the key issues of human existence. Modern education is developing in the conditions of civilizational crisis. People should give response to the challenges of the time, but he is the cause of negative changes in the world. He loses spiritual values, the meaning of life. It reflects the drama of the twentieth century with its world wars, totalitarian regimes, economic crises. 
The problem of human speaks about the rise of the anthropological trends in modern education. The expansion of this subject area scholars see the creation of effective conditions for the realization of human capacities for discovery, for creativity, for freedom of expression, to realization of their values. However, the declaration of anthropological priorities not supported by competent teachers, managerial solutions. Developing human capacity in the Russian education is hindered by the change of ideology, the uncertainty of the essential characteristics of the human model, defining the direction of the formation of new educational practices. The solution of the anthropological problems is often as a declaration or as a matter of course, obvious. Meanwhile, the efficiency of human capacity-building requires serious study of emerging anthropological practice. The problem lies in the lack of development of the methodology underpinning the organization of anthropological practice.

In the analytical report «the System crisis of domestic education as a threat to national security of Russia and ways of its overcoming» (hands. project team V. I. Slobodchikov), highlighted the risks posed by insufficient readiness of the anthropological components: the risk of losing a significant part of the population of civic identity, the loss of unity of the nation, the loss of understanding of its cultural and historical role in the world cultural process, erosion of continuity of generations, family disintegration, the loss of spiritual and cultural traditions; the transformation of education in the field of bureaucratically organized services. The developing of human in education is constrained by factors: the growing ideological vacuum, the formation of a utilitarian approach to the person, the destruction of the purity of childhood.

V.I. Slobodchikov introduces the idea of the necessity of forming the educational anthropological practices, serving as a way of «production and reproduction of humanity in the new conditions» [1]. Anthropological practice acts as an essential component of the public practices aimed at the development of culture, society and person.

A feature of education becomes creativity in developing new educational models. That characteristics of emerging anthropological practice. Thus, the analysis of the activities of the schools shows a growth point centred perspective: «Human health», «Human and inner world», «Human and outer world».

1. The «Human health» as problem through all components of the educational program in many schools. Anthropological characteristics are viewed in the specification of educational outcomes in relation: the formation of installation on a healthy lifestyle; awareness of health as a value.

Health-promoting activity is one of priority directions in the educational institutions of the Vsevolozhsk district, which is located in the southern part of unique natural features, rich pine forests, washed by the waters of lake Ladoga, Karelian isthmus. It is an area for physical culture and sports. Created centers, bases for active rest workouts. Note that installation on formation of a healthy way of life is connected with education of active life position of students, the need to more fully take into account the age, needs and interests of the person. Issues of preservation and strengthening of health are considered in the context of the structure of school life, which involves a number of components.

- Cognitive component: the development of training programs, training teachers to active methods of formation a healthy lifestyle.

- Health care component of the internal environment. It includes: air and thermal conditions; light mode, preventing the appearance of visual dysfunctions; furniture to the anthropometric data.

- Health care component of the external environment. There are - school ice arena - parks - coastal area of lake Ladoga.

The paper demonstrates the possibilities of anthropological practice as:

- formation of a multi-component healthy lifestyle;

- disclosure of the value of health meanings of education; 
- development of programs and projects on formation of life health in educational process.

2. The problem «Human and inner world» is revealed in the implementation of individual characteristics and talents of the student. There is the interaction with the institutions of additional education the effective way. The target highlighted the processes of self-development, self-education, selfrealization as characteristic of pedagogical anthropology.

This activity takes place in the framework of additional education - a system of clubs with different activities: poetic, theatrical, scientific, artistic, modeling, robotics. At school number 23 of Saint-Petersburg selected the concept of «creativity in free flight», when the activity of children is determined by their imagination. At school number 210 of St. Petersburg established the classical ballet under the direction of graduates of the Academy of Russian ballet named A. Y. Vaganova. The repertoire of the school are ballets «the Nutcracker», "Thumbelina». Another area of anthropological practice are projects for children aimed at the formation of different competencies required in life.

Thus, in solving the problem of «Human and inner world» appear growth point of anthropological practice:

- development of individually-oriented systems and programs of education;

- specification and extension of the tasks in the field of updating the content, forms, methods, technologies support a child's giftedness;

- using project activities.

3. The formation of childrens and adult community in modern education illustrates the problem of «Human and the outerworld» in the new sociocultural environment.

Example of interaction of children, adolescents and adults supports children's public organization «the Seventh dimension» school number 7 of Ostrov-town the Pskov region. Here the tasks of upbringing of students ' skills of self-organization on the basis of respect for the views and beliefs of other people and the search of new forms of socialization. Dedicated game area where developed role-playing, modeling a particular situation on the basis of the script of the legend. Thus, in the imaginary conditions of the game are designed, the types of interactions, behaviors, ways of self-assertion and self-expression.

Another example of the interplay of children serves Young people Republic Vsevolozhsk the Leningrad region. There is a system of clubs: «Life Line», «Pulse», «South Park», «Energy» etc.

Thus, in the actual experience are the following manifestations of anthropological practice:

- various forms of children's organizations, giving the opportunity to find friends, to demonstrate their abilities in socially significant activities;

- design experience in the games;

- development of club activities of interest.

It should be noted that in the emerging environment, there are anthropological characteristics of teacher's mission. They are reflected in the statement of task:

- improve the professional and methodological culture;

- strengthening creative direction in the organization of individual and independent activity of the student.

Anthropological characteristics are reviewed in the development of a code of ethics. So, developed in school number 490, Saint Petersburg «the Code of professional ethics of pedagogical workers» serves to preserve in the educational process moral responsibility of the teacher for the upbringing of the citizen of Russia; increase of the social significance, prestige of pedagogical work. Stands out the moral stance of the teacher, developing high selfdiscipline, the ability to recognize and correct their own mistakes. The teacher should observe the grammatical rules of the language, culture of speech and writing, not to use himself and to 
prevent the use of profanities, vulgar, obscene or insulting phrases. At the forefront of humane attitude to the child, tact, not allowing any expression of superiority. Stresses the importance of pedagogical support: skills to help the child, to strengthen his faith in own strength and ability, to encourage the development of positive traits and relationships, show the ways of improvement.

Highlight, in this context, also activities of non-commercial partnership «Human Education» as a social movement «...for the creative transformation of education», created in the framework of the St. Petersburg branch of the Institute of education management RAO. The concept of «mission teacher» is topic of discussion. The mission here comes from his own understanding teacher objectives, nature and purposes of education roles of teacher and student. The mission is seen as the destiny of human, on the one hand, beyond his personal life, on the other - defined by the personal meanings and experiences.

In the proceedings of «The teacher with oneself» in the publications of teachers representations about the mission of the teacher: how about his inner freedom to express their stance and ability to convey it to children; how the ability to get away from the standardization of the lesson by giving children the knowledge, human warmth and kindness; as for mental labor, when the whole educational process, literally, «passes through itself» [2].

Thus, the mission of the teacher is manifested in the creative search:

- to build teacher pedagogical systems that reflect its values;

- allocation raising the value of the personality of the teacher, acting as an example of humanism and high moral qualities;

- selection of new meanings of professional activity.

The given examples testify to the ways of the formation of the postnonclassical paradigm, highlighting the increasing role of the subject in cognition and practical activity. Emerging anthropological practice acquires the characteristic of object of scientific research, the specifics of which reflect the process of overcoming the utilitarian aspects of education, limiting the building of human narrow sphere of needs of production and consumption.

$$
* * *
$$

1. Slobodchikov V. I. anthropological School practices in contemporary образовании.-http://www.portalslovo.ru/pedagogy/44144.php

2. The teacher with oneself SPb.nauch.articles/Ed.-comp. M. N. Kozhevnikova. - SPb.: Ed. "Lema", FGNU principle that gains RAO, 2014. $-176 \mathrm{p}$. 